\title{
Tensile Fracture Behavior of 316L Austenitic Stainless Steel Manufactured by Hot Isostatic Pressing
}

\begin{abstract}
A.J. COOPER, W.J. BRAYSHAW, and A.H. SHERRY
Herein we investigate how the oxygen content in hot isostatically pressed (HIP'd) 316L stainless steel affects the mechanical properties and tensile fracture behavior. This work follows on from previous studies, which aimed to understand the effect of oxygen content on the Charpy impact toughness of HIP'd steel. We expand on the work by performing room-temperature tensile testing on different heats of $316 \mathrm{~L}$ stainless steel, which contain different levels of interstitial elements (carbon and nitrogen) as well as oxygen in the bulk material. Throughout the work we repeat the experiments on conventionally forged $316 \mathrm{~L}$ steel as a reference material. The analysis of the work indicates that oxygen does not contribute to a measureable solution strengthening mechanism, as is the case with carbon and nitrogen in austenitic stainless steels (Werner in Mater Sci Eng A 101:93-98, 1988). Neither does oxygen, in the form of oxide inclusions, contribute to precipitation hardening due to the size and spacing of particles. However, the oxide particles do influence fracture behavior; fractography of the failed tension test specimens indicates that the average ductile dimple size is related to the oxygen content in the bulk material, the results of which support an on-going hypothesis relating oxygen content in HIP'd steels to their fracture mechanisms by providing additional sites for the initiation of ductile damage in the form of voids.
\end{abstract}

https://doi.org/10.1007/s11661-018-4518-2

(C) The Author(s) 2018. This article is an open access publication

\section{INTRODUCTION}

HoT Isostatic Pressing (HIP) is a metal forming process that employs the use of high temperature and isostatically controlled pressure to consolidate metal powder, of required chemistry, into bulk components. The technique is particularly well suited to the fabrication of components which require a relatively complex geometry, since the HIP'd part takes the shape of the pre-fabricated vessel or mold within which it is compressed, and HIP is thus known as an example of near net shape manufacture. ${ }^{[1,2]}$ This makes HIP an alternative route to, for example, the production of multi-connected pipes, which would require additional machining and welding of forged pipes to produce a component of the same geometry. The ability to bypass unnecessary production stages is advantageous not only to the

A.J. COOPER and W.J. BRAYSHAW are with the School of Materials, University of Manchester, Oxford Road, Manchester M13 9PL, UK Contact e-mail: adam.cooper@manchester.ac.uk A.H. SHERRY is with the School of Materials, University of Manchester and also with the National Nuclear Laboratory, Birchwood Park, Warrington, WA3 6AE, UK.

Manuscript submitted October 4, 2017.

Article published online February 21, 2018 manufacturer in terms of reducing manufacturing time and associated costs, but also to structural integrity assessment procedures. This is because HIP'd components can exhibit an isotropic microstructure and homogeneous material properties as a result of the isostatically controlled temperature and pressure during the HIP cycle. ${ }^{[3-6]}$ HIP components therefore do not exhibit the microstructural and mechanical directionality $^{[7-9]}$ as is often seen in forgings and castings, and the omission of welding means that complex microstructural transitions and weld residual stresses can be avoided altogether, resulting in components with enhanced material performance when exposed to demanding environments and stress.

Because of the clear merits associated with HIP'd components, there is an increasing desire among engineers to incorporate HIP technology into the nuclear sector (HIP has been popular within the oil and gas sector for many years) either in terms of new reactor design or in the replacement of parts currently in service. However, due to the demanding regulatory control within the nuclear sector, and also partly due to the high costs currently associated with near net shape manufacture, ${ }^{[10]}$ HIP is only recently making a contribution to the production of components required for use in nuclear environments. ${ }^{[11]}$ As a result, there have been increased efforts to enhance the understanding of 
fundamental metallurgical and mechanical behavioral differences between HIP and chemically equivalent forged materials, highlighted recently by studies on the microstructural development during $\mathrm{HIP}^{[12]}$ and to demonstrate that HIP materials display enhanced material properties over their forged counterparts; ${ }^{[13-17]}$ HIP technology needs to offer more than just an easier fabrication methodology before it can be justified as a replacement to conventional 'tried and tested' manufacture routes.

HIP steels are generally claimed to exhibit higher strength, ${ }^{[1]}$ toughness and corrosion resistance ${ }^{[9,18]}$ than forgings and castings, and this is usually attributed to the finer grain size and equiaxed microstructure of the HIP'd material ${ }^{[19]}$ as well as lack of porosity. ${ }^{[1]}$ However, one of the fundamental chemical differences between HIP'd and forged steels lies in the oxygen content which resides in the HIP steel after all manufacture and heat treatment stages are completed; oxygen concentrations are typically an order of magnitude greater than those of equivalently graded forged steels, which exhibit typical oxygen concentrations of greater than $100 \mathrm{ppm}$, in contrast to $10-20 \mathrm{ppm}$ typically measured in forgings. ${ }^{[13,14]}$

Traditionally, oxygen and nitrogen have not been of significant interest to forging and casting metallurgists due to the comparatively low levels that exist in the microstructures of materials produced from such techniques, and as a result, oxygen and nitrogen concentrations are rarely listed in chemical composition data on material certificates. However, partly due to the high surface area of the metal powder required for HIP, and as a result of the many stages of powder handling throughout the manufacture process, oxygen pickup in the form of powder surface oxidation is difficult to avoid.

While it has been reported that the effects of powder surface oxidation are detrimental to the impact properties of HIP'd steels, ${ }^{[20,21]}$ the authors have recently published a series of papers ${ }^{[13-16]}$ which investigate and quantify the effects of oxygen on material impact toughness and the mechanisms of fracture, in which it has been established that enhanced oxygen concentrations in HIP stainless steel result in a greater volume fraction of oxide inclusions in the microstructure, thereby facilitating the ductile fracture mechanism by acting as additional sites for the nucleation, and subsequent growth and coalescence of microvoids in the plastically deforming matrix. Because of the increased volume fraction of initiation sites in the HIP steels, and the reduced inter-void distances, void coalescence can occur at lower values of plastic strain since voids have smaller distances over which they need to grow to coalesce with adjacent voids. We expand on the work here, by investigating whether the higher concentrations of oxygen in the HIP steels are detrimental to material strength or whether the effects are only restricted to the ductile fracture mechanism. Fractography of the failed tensile test specimens has been employed to study the relationship between oxygen (oxide) content and the average diameter of the ductile dimples present at failure.

\section{EXPERIMENTAL}

Four heats of HIP'd 316L were obtained from the Electrical Power Research Institute (EPRI, USA) containing final-material oxygen concentrations of 100, 100, 145, and $190 \mathrm{ppm}$, respectively, with the aim to probe the effect of oxygen concentration on ductile fracture. Material HIP100A contained a nitrogen concentration (1400 ppm) that is out of specification according to ASTM. ${ }^{[22]}$ The materials have been labeled according to their oxygen contents, since this formed the initial study, ${ }^{[14]}$ and specimen labels are listed in Table I along with elemental compositions (pct wt) and grain sizes. For the HIP'd materials studied, independent batches of 316L stainless steel powders were heated to $1423 \mathrm{~K}$ $\left(1150{ }^{\circ} \mathrm{C}\right)$ under 1050 bar pressure for a total period of 3.5 hours. All HIP'd materials were post-HIP heat treated to $1313 \mathrm{~K} \quad\left(1040{ }^{\circ} \mathrm{C} \pm 4{ }^{\circ} \mathrm{C}\right)$ and water

Table I. Elemental Composition

\begin{tabular}{|c|c|c|c|c|c|c|c|c|c|c|c|c|c|c|}
\hline \multirow{2}{*}{$\begin{array}{l}\text { ASTM A988/A988M-16 } \\
\text { Spec. }\end{array}$} & $\begin{array}{l}\text { Grain Size } \\
\quad(\mu \mathrm{m})\end{array}$ & \multicolumn{2}{|c|}{$\begin{array}{l}\text { Standard } \\
\text { Deviation }\end{array}$} & $\mathrm{C}$ & $\mathrm{Si}$ & $\mathrm{Mn}$ & $\mathrm{P}$ & $\mathrm{S}$ & $\mathrm{Cr}$ & Mo & \multicolumn{2}{|c|}{$\mathrm{Ni}$} & \multirow{2}{*}{$\begin{array}{l}\text { Al } \\
-\end{array}$} & \multirow{2}{*}{$\begin{array}{l}\text { As } \\
-\end{array}$} \\
\hline & - & - & & $<0.08$ & $<1.00$ & $<2.00$ & $0<0.045$ & $<0.031$ & $16.0-18.0$ & $02.00-3$ & .0010 .0 & 14.0 & & \\
\hline F316L & 60 & 24 & & 0.027 & 0.33 & 1.86 & 0.034 & 0.003 & 17.5 & 2.03 & 10. & & $<0.01$ & 0.011 \\
\hline HIP100A & 51 & 11 & & 0.024 & 0.81 & 0.98 & 0.009 & 0.006 & 17.2 & 2.45 & 13. & & $<0.01$ & $1<0.005$ \\
\hline HIP100B & 58 & 16 & & 0.016 & 0.80 & 0.98 & 0.015 & 0.006 & 17.4 & 2.49 & 12. & & $<0.01$ & $1<0.005$ \\
\hline HIP145 & 31 & 9 & & 0.016 & 0.53 & 1.76 & 0.009 & 0.009 & 17.5 & 2.40 & 12. & & $<0.01$ & $1<0.005$ \\
\hline HIP190 & 32 & 6 & & 0.011 & 0.54 & 1.34 & 0.009 & 0.008 & 16.1 & 2.19 & 13. & & $<0.01$ & $1<0.005$ \\
\hline ASTM A988/A988M-16 $6^{[22]}$ & $\mathrm{B}$ & $\mathrm{Co}$ & $\mathrm{Cu}$ & $\mathrm{Nb}$ & & $\mathrm{Pb}$ & $\mathrm{Sn}$ & $\mathrm{Ti}$ & V & W & $\mathrm{Ca}$ & $\mathrm{N} / \mathrm{p}$ & ppm & $\mathrm{O} / \mathrm{ppm}$ \\
\hline Spec. & - & - & - & - & & - & - & - & - & - & - & & - & - \\
\hline F316L & $<0.001$ & 0.15 & 0.33 & $3<0.0$ & & 0.002 & 0.009 & $<0.001$ & 0.04 & $<0.05$ & 0.001 & & 880 & 23 \\
\hline HIP100A & $<0.001$ & 0.02 & 0.05 & $5<0.0$ & & 0.002 & $<0.005$ & $<0.001$ & 0.02 & $<0.05$ & $<0.001$ & & 400 & 100 \\
\hline HIP100B & 0.001 & 0.01 & 0.05 & $5<0.0$ & & 0.002 & $<0.005$ & $<0.001$ & 0.02 & $<0.05$ & 0.001 & & 000 & 100 \\
\hline HIP145 & $<0.001$ & 0.02 & 0.06 & $6<0.0$ & & 0.002 & $<0.005$ & $<0.001$ & 0.02 & $<0.05$ & 0.001 & & 750 & 145 \\
\hline HIP190 & 0.002 & 0.03 & 0.05 & 0.0 & & 0.002 & $<0.005$ & $<0.001$ & 0.01 & $<0.05$ & $<0.001$ & & 380 & 190 \\
\hline
\end{tabular}


quenched. Forged 316L material was provided by Rolls Royce, UK, and heat treated to $1323 \mathrm{~K}\left(1050^{\circ} \mathrm{C}\right)$ and water quenched.

Electron microscopy of sectioned specimens and fracture surfaces was performed using an FEI Quanta 650 scanning electron microscope (SEM) and an FEI Sirion SEM, both equipped with field emission guns and Electron Back-Scattered Diffraction (EBSD) detectors, and a Hitachi S-3700 SEM equipped with Oxford Instruments INCA X-ACT energy dispersive spectroscopy for semi-quantitative chemical analysis. Scanning electron microscopy was performed under vacuum using a $20 \mathrm{kV}$ accelerating voltage and a spot size of $4.0 \mathrm{~nm}$, at a working distance of approximately $10 \mathrm{~mm}$.

Forged $316 \mathrm{~L}$ tensile test specimens were extracted in the longitudinal (rolling) direction of a forged plate. HIP316L tensile test specimens were extracted in the axial direction of the HIP cylinder. Round bar tension test specimens were machined in accordance with ASTM E8/

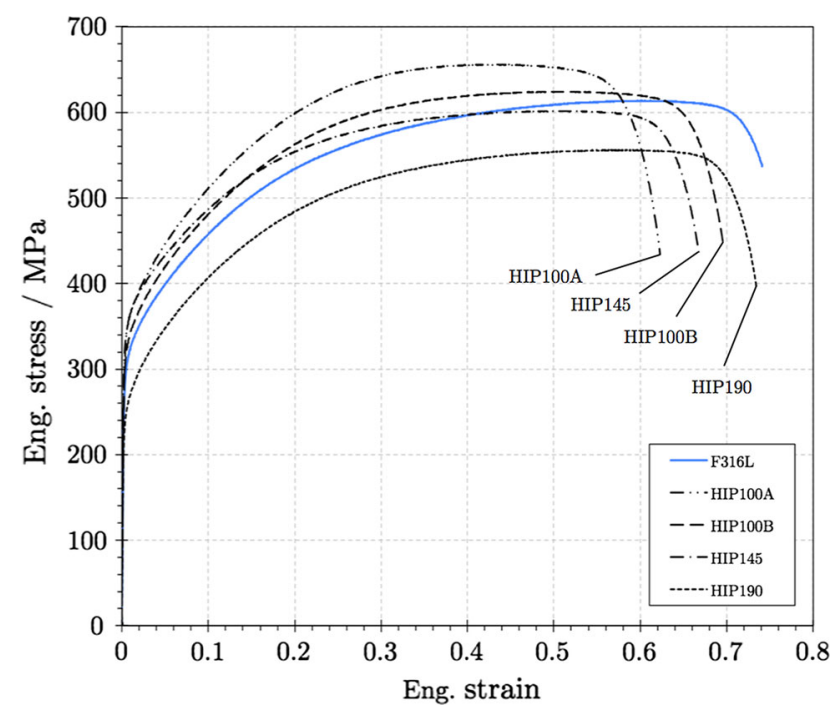

Fig. 1-Tensile stress/strain curves for Forged and HIP'd 316L showing complete stress/strain data.
E8M recommended dimensions, with a gage length of 50 $\mathrm{mm}$, gage diameter of $8 \mathrm{~mm}$, and M12 thread. ${ }^{[23]}$ Tensile testing was conducted in displacement control at a strain rate of $0.5 \mathrm{~min}^{-1}$ at ambient temperature. Three tensile tests were performed for each material and condition, and the yield strength and UTS values were taken as an average of the three tests. Reduction in area (pct RA) was determined using digital Vernier calipers, by measuring the portion of least diameter in the necked region of the failed tensile specimens.

Specimens prepared for metallurgical analysis were sectioned, mounted, ground, and polished in accordance with the recommended procedures in ASTM practice E3-11. ${ }^{[24]}$ Grain size measurements were obtained by etching specimens in $10 \mathrm{wt}$ pct oxalic acid solution for between 20 and 40 seconds in order to reveal the microstructure optically, and measured via the linear intercept method in accordance with ASTM E112-96; ${ }^{[25]}$ measurements were taken over three different areas and approximately 250 grains contributed to the average grain size. The average ductile dimple size on the fracture surface of tested specimens was also determined using the linear intercept method, as detailed in ASTM E112-96 $6^{[25]}$ for measuring average grain size. Several regions of interest on the fracture surface were selected in order to sample over a greater area; this was achieved by measuring features over several micrographs. However, because of the undulating topography of ductile fracture surfaces, this reduced the analytical areas to those that were perpendicular to the electron detector in the SEM, since linear intercept analysis on non-perpendicular planes would result in inaccurate diameter measurements. To address this, efforts were made to analyze dimples that appeared spherical in shape (showing no signs of elongation and/or shear) since this shape would indicate visual inspection normal to the void. For each specimen, approximately 1000 ductile dimples were included in the average diameter calculations. Elemental analysis was performed at The Welding Institute (TWI, UK) using optical emission spectroscopy and direct spark analysis.

Ductile damage in the necked region of tensile specimens was assessed using SEM on regions $c a$.

Table II. Mechanical Properties for all Specimens

\begin{tabular}{|c|c|c|c|c|c|c|c|c|c|c|}
\hline & $\begin{array}{l}0.2 \text { Pct Yield Strength } \\
\left(\sigma_{\mathrm{y}}\right)(\mathrm{MPa})\end{array}$ & $\begin{array}{l}\text { Ave }\left(\sigma_{\mathrm{y}}\right) \\
(\mathrm{MPa})\end{array}$ & $\begin{array}{l}\text { Ultimate Tensile Strength } \\
\text { (UTS) (MPa) }\end{array}$ & $\begin{array}{l}\text { Ave UTS } \\
\text { (MPa) }\end{array}$ & $\begin{array}{l}\text { Pct } \\
\text { RA }\end{array}$ & $\begin{array}{l}\text { Ave Pct } \\
\text { RA }\end{array}$ & $\begin{array}{l}\text { Pct } \\
\text { EL }\end{array}$ & $\begin{array}{l}\text { Ave Pct } \\
\text { EL }\end{array}$ & $\begin{array}{l}\varepsilon \text { at } \\
\text { UTS }\end{array}$ & $\begin{array}{l}\text { Ave } \varepsilon \text { at } \\
\text { UTS }\end{array}$ \\
\hline \multirow[t]{3}{*}{ F316L } & 293 & 279 & 614 & 611 & 83.2 & 83.7 & 0.74 & 0.74 & 0.6 & 0.60 \\
\hline & 273 & & 610 & & 84.5 & & 0.74 & & 0.62 & \\
\hline & 271 & & 609 & & 83.5 & & 0.75 & & 0.58 & \\
\hline \multirow[t]{3}{*}{ HIP100A } & 333 & 334 & 663 & 658 & 78.6 & 75.6 & 0.59 & 0.61 & 0.44 & 0.43 \\
\hline & 331 & & 656 & & 79.2 & & 0.62 & & 0.43 & \\
\hline & 337 & & 654 & & 78.1 & & 0.61 & & 0.42 & \\
\hline \multirow[t]{3}{*}{ HIP100B } & 326 & 323 & 641 & 630 & 75.0 & 78.6 & 0.67 & 0.69 & 0.48 & 0.48 \\
\hline & 331 & & 623 & & 75.2 & & 0.71 & & 0.47 & \\
\hline & 312 & & 625 & & 76.5 & & 0.7 & & 0.5 & \\
\hline \multirow[t]{3}{*}{ HIP145 } & 334 & 324 & 620 & 607 & 75.7 & 75.6 & 0.66 & 0.67 & 0.47 & 0.50 \\
\hline & 329 & & 602 & & 76.7 & & 0.67 & & 0.54 & \\
\hline & 310 & & 600 & & 74.2 & & 0.69 & & 0.49 & \\
\hline \multirow[t]{3}{*}{ HIP190 } & 236 & 249 & 571 & 561 & 74.7 & 74.8 & 0.71 & 0.73 & 0.54 & 0.55 \\
\hline & 246 & & 556 & & 74.9 & & 0.74 & & 0.57 & \\
\hline & 266 & & 556 & & 74.9 & & 0.75 & & 0.55 & \\
\hline
\end{tabular}


$400 \mu \mathrm{m}$ below the fracture surface. Several slices were assessed per each specimen in order to improve statistical accuracy. The area fraction (pct) and nearest neighbor distance of the ductile voids were measured using Image J and gray scale threshold image analysis. The nearest neighbor distance was calculated using the Nearest Neighbor Distance ImageJ plugin (programmed by Yuxiong $\mathrm{MaO}^{[26]}$ ) which calculates the shortest distance between the centroids of neighboring features.

\section{RESULTS}

Table I shows the chemical compositions and grain sizes of the materials employed in this study, and indicates that all materials are within specification to A988/A988M-16. ${ }^{[22]}$ However, although nitrogen limits nitrogen content that exceeds the specification maximum limit set by ASTM A240/A240M-17 $7^{[27]}$ by over $400 \mathrm{ppm}$. Oxygen concentrations are not considered in ASTM A988/A988M-16 $6^{[22]}$ and are only considered in the argon gas purity in ASTM A180-15. ${ }^{[28]}$ The grain by $c a .30 \mu \mathrm{m}$, with F136L $(60 \mu \mathrm{m})$ and HIP100B $(53 \mu \mathrm{m})$ exhibiting grain sizes approximately double those of HIP145 $(30 \mu \mathrm{m})$ and the HIP190 $(30 \mu \mathrm{m})$ specimens. Based on the well-known Hall-Petch relationship, ${ }^{[29,30]}$ it has been calculated that yield strength would be subjected to equivalent heat treatments, there is a noticeable difference in grain size between the HIP heats, with the higher oxygen concentration heats exhibiting a finer microstructure. The reason for this is currently not understood, but could be linked to oxide particles hindering grain growth during thermal treatment. Due to previous studies where significant microstructural analyses were performed on these materials, the microstructures are not included here and can instead be viewed at. ${ }^{[14]}$

The interstitial elements carbon and nitrogen, although largely within specification, vary considerably from heat to heat, with carbon ranging between 0.011 and $0.027 \mathrm{wt}$ pct, and nitrogen ranging between 0.038 wt pct $(380 \mathrm{ppm})$ and $0.14 \mathrm{wt}$ pct $(1400 \mathrm{ppm})$. Because of these differences in chemistry, it was challenging to directly compare experimentally determined mechanical properties on a like-for-like basis.

Figure 1 illustrates the tensile test data for all specimens, showing the engineering stress/strain behavior to failure. For the purpose of clarity, a single representative stress strain curve of a total of three repeated tests has been plotted for each heat. The different heats display significant differences in both strength and ductility, which at first appears to correlate with the oxygen concentrations of the materials. However, this is before considering the differences in grain size and the interstitial alloying elements' strengthening behavior.

Table II summarizes average yield strength $\left(\sigma_{\mathrm{y}}\right)$, ultimate tensile strength (UTS), reduction in area (pct RA), and elongation (pct EL) data for each heat. are not stated in A988/A988M-16, HIP100A exhibits a sizes (diameter) of the HIP and forged specimens differ expected to vary by $c a$. $40 \mathrm{MPa}$ between materials. It is interesting to note that despite the materials being

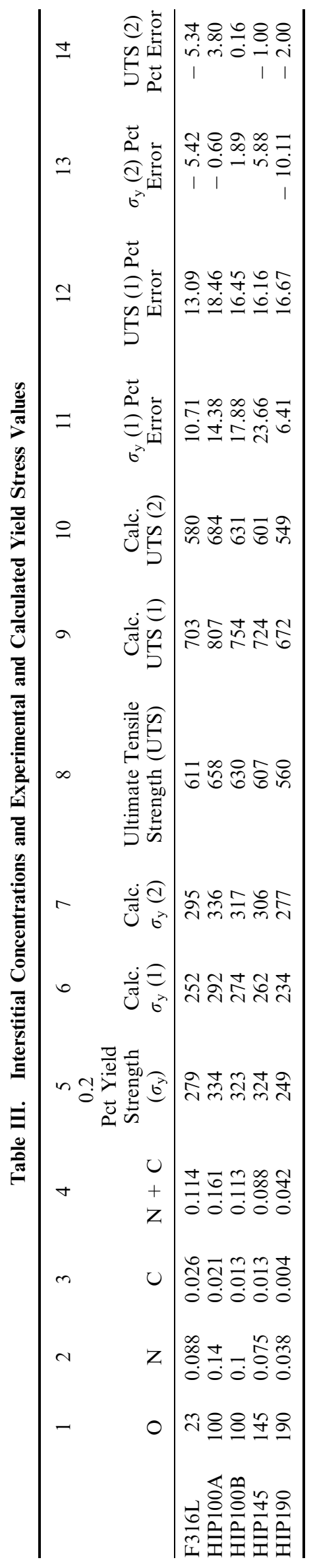




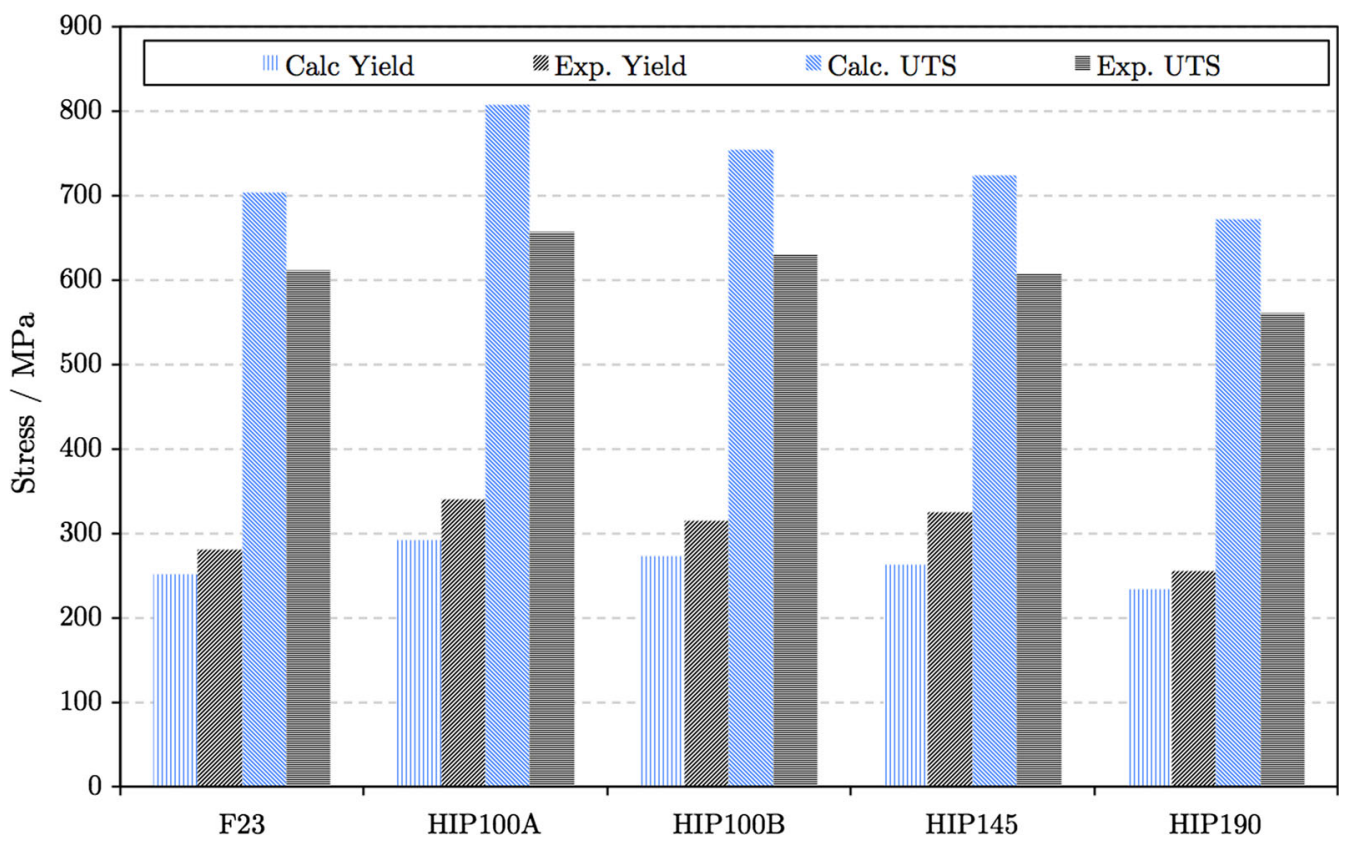

Fig. 2-Experimental and calculated yield strength (0.2 pct proof) for all test specimens using Eqs. [1] and [2].

In order to probe the effect of oxygen on strength, it was important to quantify strength in terms of the material chemical compositions and grain sizes. This was addressed by using the well-known regression formula derived by Irvine et al., ${ }^{[31]}$ which quantifies stainless steel yield strength based on chemical composition and grain size:

$$
\begin{aligned}
\sigma_{\mathrm{y}}= & 15.4\{4.4+23(\mathrm{C})+1.3(\mathrm{Si})+0.24(\mathrm{Cr})+0.94(\mathrm{Mo}) \\
& +1.2(\mathrm{~V})+0.29(\mathrm{~W})+2.6(\mathrm{Nb})+1.7(\mathrm{Ti})+0.82(\mathrm{Al}) \\
& \left.+32(\mathrm{~N})+0.16(\delta-\text { ferrite })+0.46 \mathrm{~d}^{-\frac{1}{2}}\right\}
\end{aligned}
$$

where each element concentration is inputted in wt pct and $\mathrm{d}$ is the grain size in $\mathrm{mm}$.

Similarly, Irvine et al. proposed a formula to predict stainless steel UTS from chemical composition and grain size:

$$
\begin{aligned}
\sigma_{\mathrm{UTS}} & =15.4\{29+34(\mathrm{C})+84(\mathrm{~N})+2.7(\mathrm{Si})+0.13(\mathrm{Ni}) \\
& \left.+1.2(\mathrm{Mo})+3.6(\mathrm{Nb})+1.9(\mathrm{Ti})+2.1(\mathrm{Al})+0.9 \mathrm{~d}^{-\frac{1}{2}}\right\},
\end{aligned}
$$

In both equations, the 15.4 coefficient is the conversion factor for converting ton in. ${ }^{-2}$ to $\mathrm{MPa}$.

These formulae have been used to successfully probe the effects of alloying element concentration (often nitrogen) on the hardness, yield strength, and tensile strength of austenitic stainless steel. ${ }^{[32-37]}$ These formulae were employed herein to calculate theoretical yield strength and UTS values for the different heats, and these are compared with the experimental values in

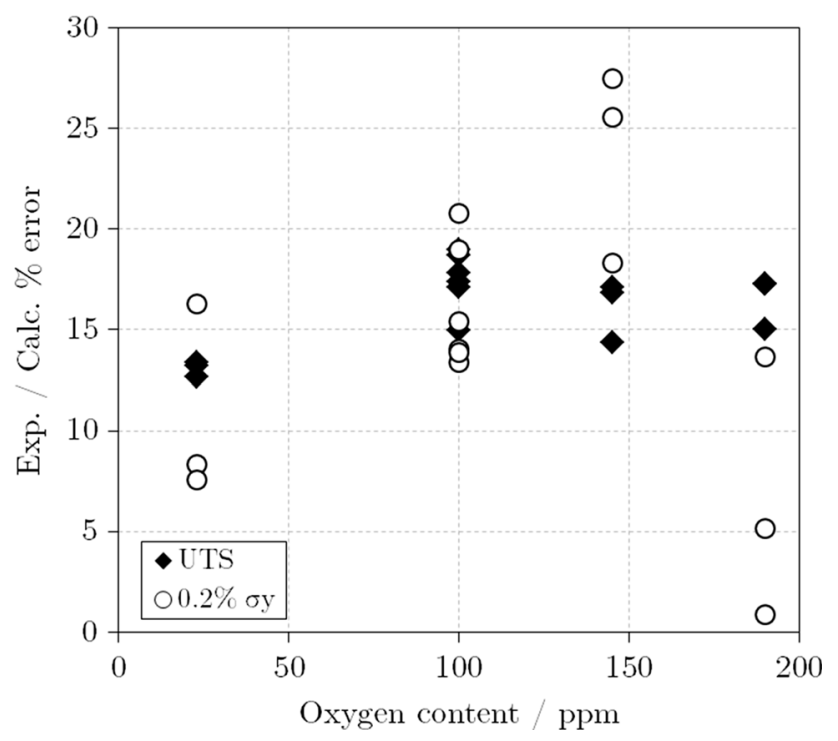

Fig. 3-Pct error between each experimentally determined 0.2 pct yield strength $(\sigma \mathrm{y})$ and the calculated 0.2 pct yield strength $(\sigma \mathrm{y})$ for each material (white data), and each experimentally determined UTS and the calculated UTS for each material (black data), presented as a function of oxygen.

Table III. Since nitrogen and carbon have the highest weighting in both equations, the chemical concentrations (wt pct) of these elements have also been tabulated, along with the total wt pet of carbon + nitrogen. The chemical compositions used for Eqs. [1] and [2] were the average wt pct values as tabulated in Table I, and it should be noted that there is an error associated with the limit of detection and standard deviation.

Delta $(\delta)$ ferrite has not been observed in any of the materials and was therefore not included in Eq. [1]. 


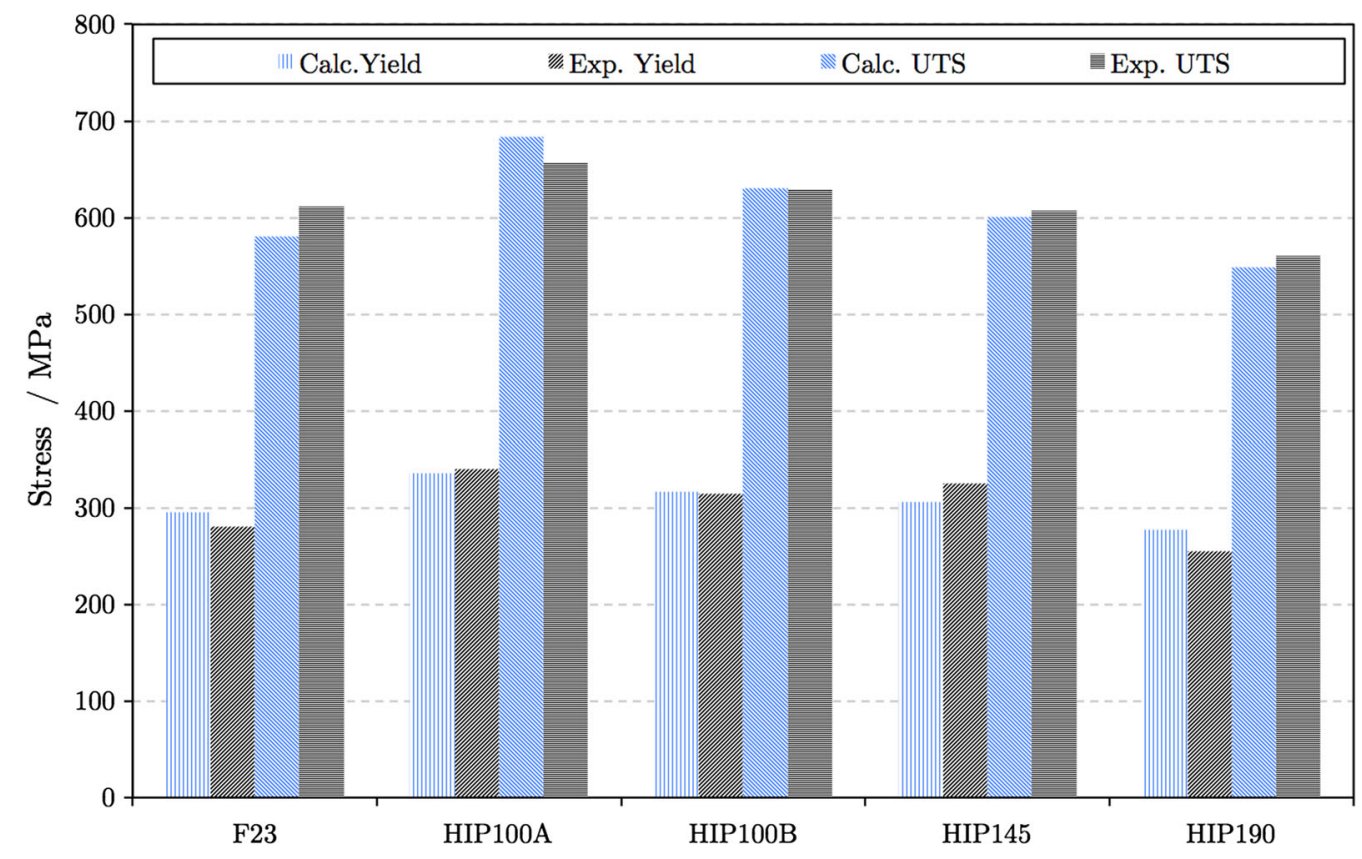

Fig. 4-Experimental and calculated yield strength (0.2 pct proof) for all test specimens using Eqs. [1] and [2] with amended regression parameters of 7.1 and 21 , respectively.

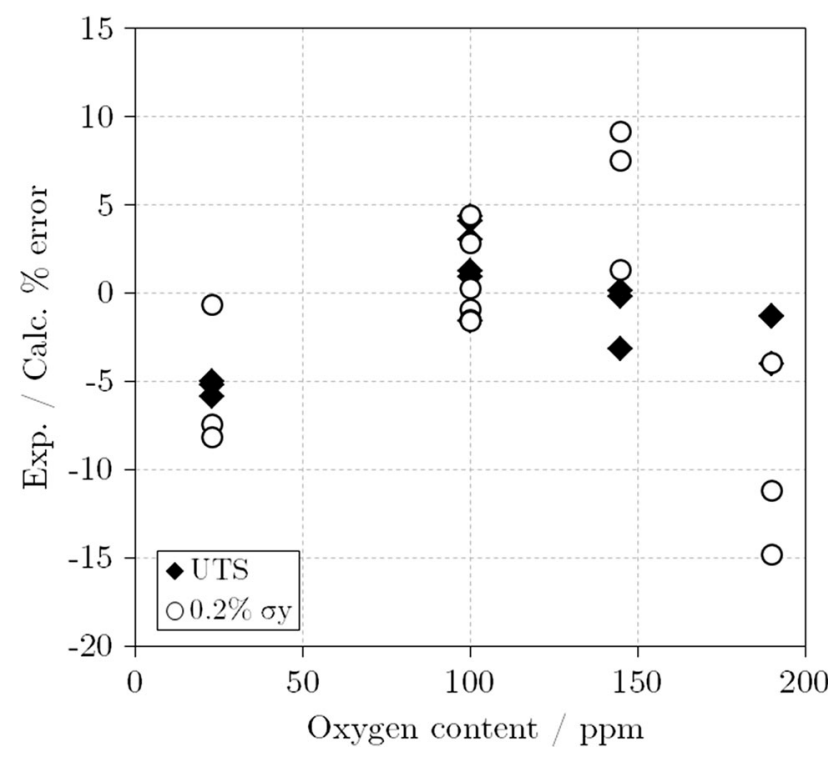

Fig. 5-Figure pct error between each experimentally determined 0.2 pct yield strength $\left(\sigma_{\mathrm{y}}\right)$ and the calculated 0.2 pct yield strength $\left(\sigma_{\mathrm{y}}\right)$ for each material (white data), and each experimentally determined UTS and the calculated UTS for each material (black data), using optimum regression parameters and presented as a function of oxygen.

Experimentally determined and calculated yield strength and UTS values are presented in Figure 2. For yield strength, the calculated yield strength values are consistently smaller than the experimental yield strength values by between 15 and $62 \mathrm{MPa}$ (6.41 to 23.66 pct). However for UTS, Eq. [2] was found to over predict UTS for all the heats by between 92 and 149 MPa (13.09 to $18.46 \mathrm{pct})$.
Since the yield strength and UTS calculations are based on material chemistry and grain size alone, any increasing discrepancy between experimental and calculated values could be related to the increasing oxygen concentration in the different heats, since no evidence of delta ferrite, other secondary phases, or porosity was observed in the various $316 \mathrm{~L}$ heats. To investigate this, Figure 3 shows the pct error between each experimentally determined $0.2 \mathrm{pct}$ yield strength $\left(\sigma_{\mathrm{y}}\right)$ and the calculated 0.2 pct yield strength $\left(\sigma_{\mathrm{y}}\right)$ for each material (white data), and each experimentally determined UTS and the calculated UTS for each material (black data), presented as a function of oxygen. For these data, the mean pct error is 14.64 and 16.14 pct for 0.2 pct yield strength $\left(\sigma_{\mathrm{y}}\right)$ and UTS, respectively.

Table III lists mean values for experimentally determined 0.2 pct yield strength $\left(\sigma_{\mathrm{y}}\right)$ (column 5), calculated 0.2 pct yield strength (column 6) experimentally determined UTS (column 8), calculated UTS (column 9), and pct error between experimental and calculated $\sigma_{\mathrm{y}}$ and UTS in columns 11 and 12 , respectively. The number (1) in the headings of columns $6,9,11$, and 12 indicates that calculations were performed using Eqs. [1] and [2].

To improve the accuracy of predicted yield and UTS from Eqs. [1] and [2], respectively, the regression parameters of 4.4 and 29 were varied iteratively in order to minimize the percentage error between calculated and experimental values. Optimum regression parameters for Eqs. [1] and [2] were found to be 7.2 and 21 , respectively, and the improved predictions are presented in Figures 4 and 5 in the same manner as Figures 2 and 3. Calculated 0.2 pet yield strength and UTS using the amended regression parameters are tabulated in Table III in columns 7 and 10. The pct error values are listed in columns 13 and 14 of Table III. 
The number (2) in headings of columns 7, 10, 13, and 14 indicates that calculations were performed using the amended regression parameters.

The percentage error between experimental and calculated yield strength and UTS is improved considerably by using the amended regression parameters of 7.1 and 21 in Eqs. [1] and [2]; the mean pct error was reduced to 1.61 and 0.9 pct for 0.2 pet yield strength $\left(\sigma_{\mathrm{y}}\right)$ and UTS, respectively. This highlights that the initial discrepancy between experimental and calculated values

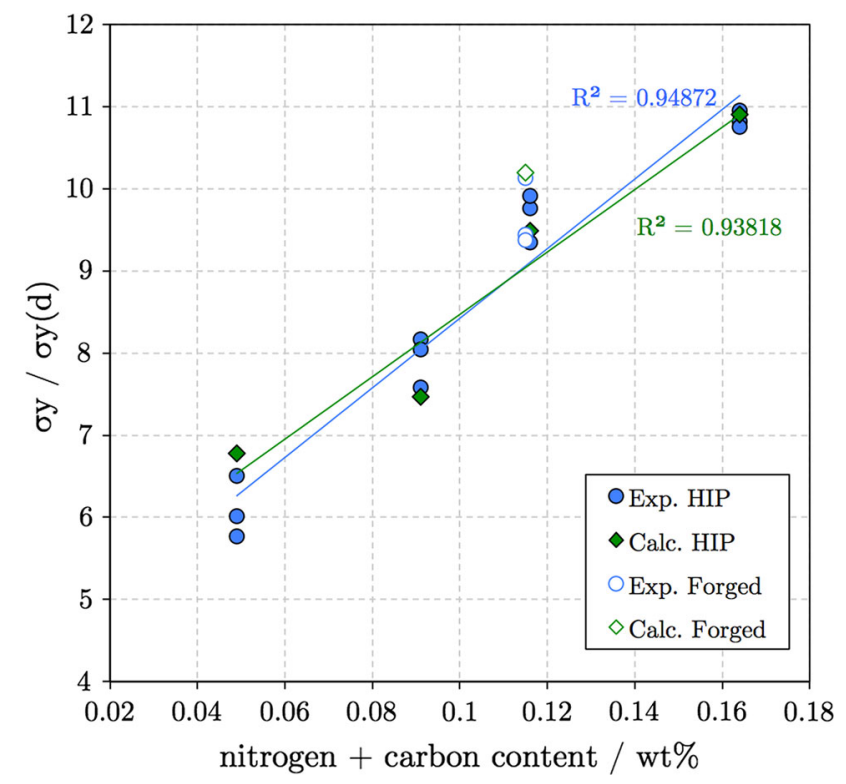

Fig. 6-Experimental and calculated yield stress values, normalized by each specimen's respective grain size contribution, and plotted as a function of total carbon and nitrogen content.

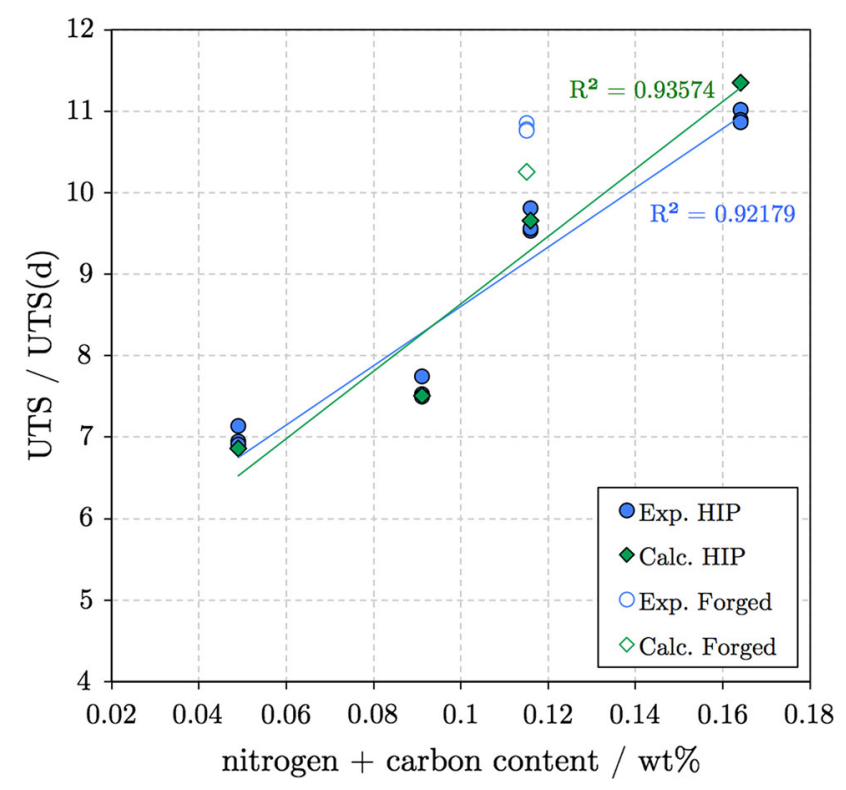

Fig. 7-Experimental and calculated UTS values, normalized by each specimen's respective grain size contribution, and plotted as a function of total carbon and nitrogen content. can be accounted for using a constant value, and is therefore unlikely that oxygen concentrations differing by over $10^{2} \mathrm{ppm}$ could account for this relatively constant discrepancy. This analysis indicates that oxygen content does not appear to play a significant role in influencing the strength of these materials, since excellent agreement between experimental and predicted yield and UTS is obtained through the use of the equations proposed by Irvine et al., modified for the heats under investigation, which do not account for oxygen in the required material chemistry.

In order to assess the experimental and calculated yield strength values as a function of their respective interstitial alloying elemental compositions (carbon + nitrogen total wt pct), it was necessary to remove the yield strength contribution from grain size effects, since all the materials exhibited slightly different grain sizes. To account for this, the grain size contribution $\left(\sigma_{\mathrm{y}(\mathrm{d})}\right)$ for each material was estimated through the Hall-Petch style relationship in Eqs. [1] and [2]:

$$
\begin{gathered}
\sigma_{\mathrm{y}(\mathrm{d})}=15.4\left\{7.1+0.46 \mathrm{~d}^{-\frac{1}{2}}\right\} \\
\sigma_{\mathrm{UTS}(\mathrm{d})}=15.4\left\{21+0.9 \mathrm{~d}^{-\frac{1}{2}}\right\} .
\end{gathered}
$$

Experimental and calculated yield strength and UTS values for each specimen were then normalized by their respective $\sigma_{\mathrm{y}(\mathrm{d})}$ and $\sigma_{\mathrm{UTS}(\mathrm{d})}$ values to glean the data in Figures 6 and 7, which shows experimental and calculated yield strength and UTS values as a function of total nitrogen and carbon concentration. The linear regression trends are within excellent agreement of one another, and the linearity indicates that material strength (both yield and UTS) is proportional to the total concentration of interstitial alloying components carbon and nitrogen, where oxygen concentration is not considered. Moreover, for the first time in this series of investigations, accounting for interstitial alloying composition and grain size has permitted accurate prediction of both HIP and forged stainless steel material properties on the same chart, indicating that any differences in mechanical behavior (but not fracture) can be accounted for through grain size and interstitial alloying composition alone, regardless of the manufacture route.

The authors have previously shown that increasing oxygen content has a detrimental effect on material impact and fracture toughness properties of HIP'd austenitic stainless steel. ${ }^{[13-15]}$ To investigate this effect in tensile specimens, metallographic analyses were performed on sectioned failed tensile specimens (Figure 8), in a region $c a .400 \mu \mathrm{m}$ below the fracture surface, in order to assess the character and extent of ductile damage in each of the specimens.

The voids below the fracture surfaces in Figure 8 were characterized in terms of their nearest neighbor distance and area fraction. This was achieved using gray scale threshold analysis in Image J software, where the contrast between voids and metal provided a good means to distinguish ductile damage from the austenite matrix. 

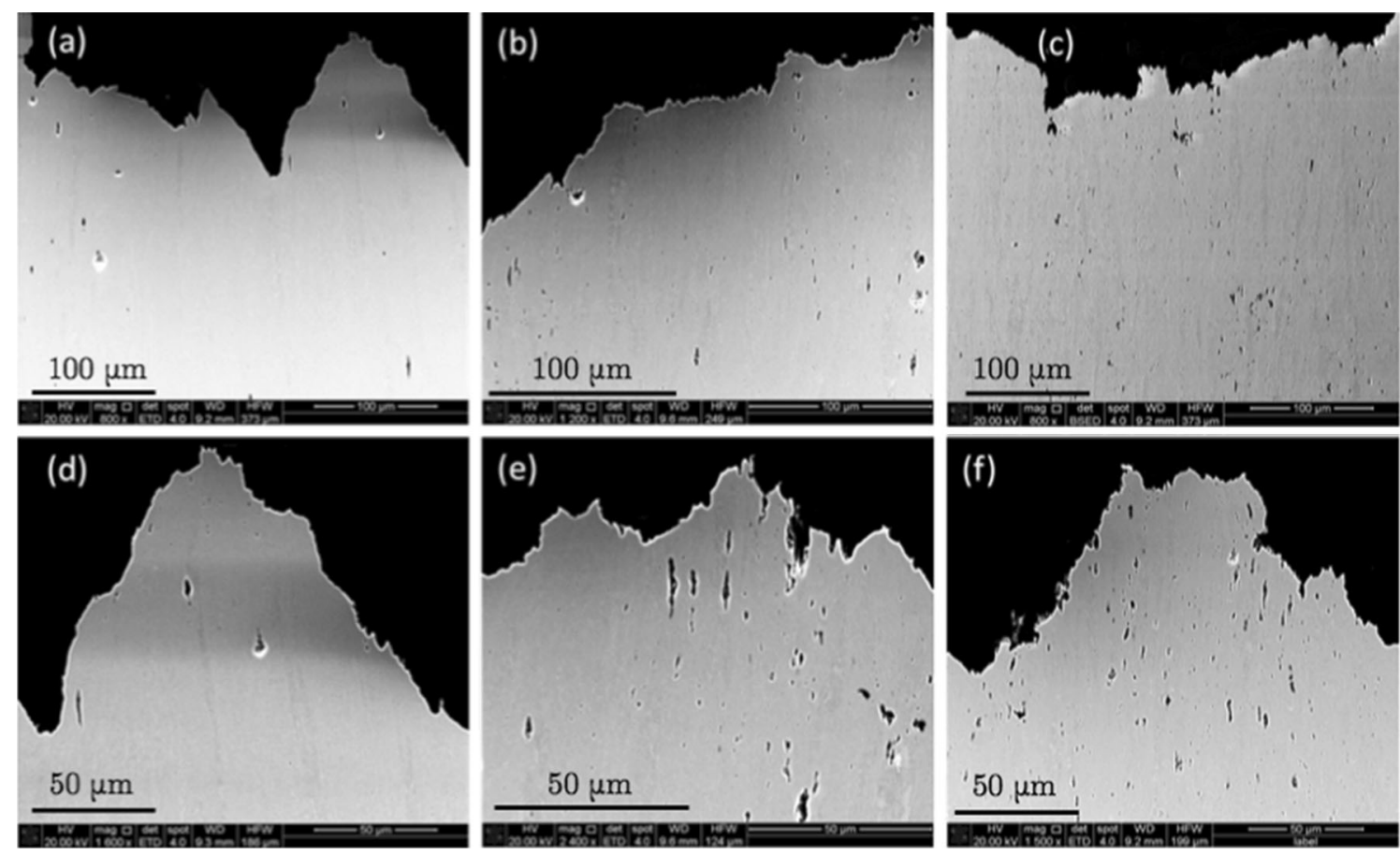

Fig. 8 - SEM images showing the extent of ductile damage below the fracture surfaces of tensile specimens for $(a, d)$ F316L, $(b, e)$ HIP100a, and $(c, f)$ HIP190 at two different magnifications.

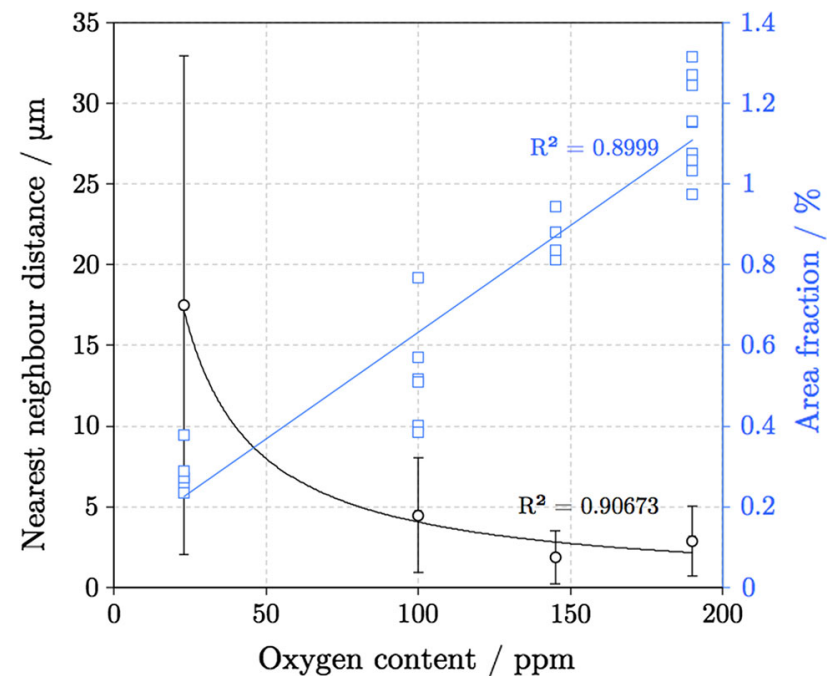

Fig. 9-Ductile damage characterized in terms of nearest neighbor distance and area fraction plotted for each specimen indicating the effect of oxygen on both parameters.

The results of nearest neighbor distance and area fraction are presented in Figure 9 and there is a clear linear relationship between the area fraction of ductile voids and oxygen concentration. Unlike strength and ductility, it was assumed that any interstitial chemical composition and grain size effects on the ductile fracture mechanism would be dwarfed by the effect of oxide inclusion concentration, since it has been shown through previous work ${ }^{[13-16]}$ that the extent of ductile void growth and coalescence is governed by the distance between initiating particles. Therefore, the data have been plotted as a function of oxygen concentration in the different heats. The correlation between nearest neighbor distance and oxygen concentration (Figure 9) is less clear, due to the scatter in the measurements; however, it is possible to approximate the average data to power law regression fit. It is possible that the larger degree of data scatter associated with the F316L specimens is due to the lower inclusion content (steel cleanliness) of the material.

Figure 10 shows secondary electron (SE) images of two typical fracture surfaces: (a) F316L and (b) HIP145. The authors previously showed ${ }^{[13,15]}$ that HIP $304 \mathrm{~L}$ stainless steel exhibited a much finer and more homogenous ductile dimple size population than forged $304 \mathrm{~L}$, where forged 304L typically exhibited a coarse network of ductile dimples interlinked by a much finer network ${ }^{[14]}$ However, examination of the fracture surfaces of the tensile specimens herein revealed networks of large voids and finer voids in both the HIP and forged specimens.

In the tensile specimens, the fracture surface was parallel to the direction of crack propagation. Examination was therefore performed perpendicular to the fracture surface, providing an unrestricted field of view, and this could explain why the network of large and small voids was previously ${ }^{[13,15]}$ not observed in HIP specimens. This network of coalesced voids consists of larger voids, which could be the result of voids nucleating at oxide inclusions, and finer voids, which could nucleate at much smaller particles such as carbides. It is notable that the voids contributing to the 'fine' networks have significantly smaller radii in the HIP specimen (10(b)) than in the forged specimen (10(a)), and the distinction between the large voids and fine voids was significantly clearer in the HIP specimens than in the 

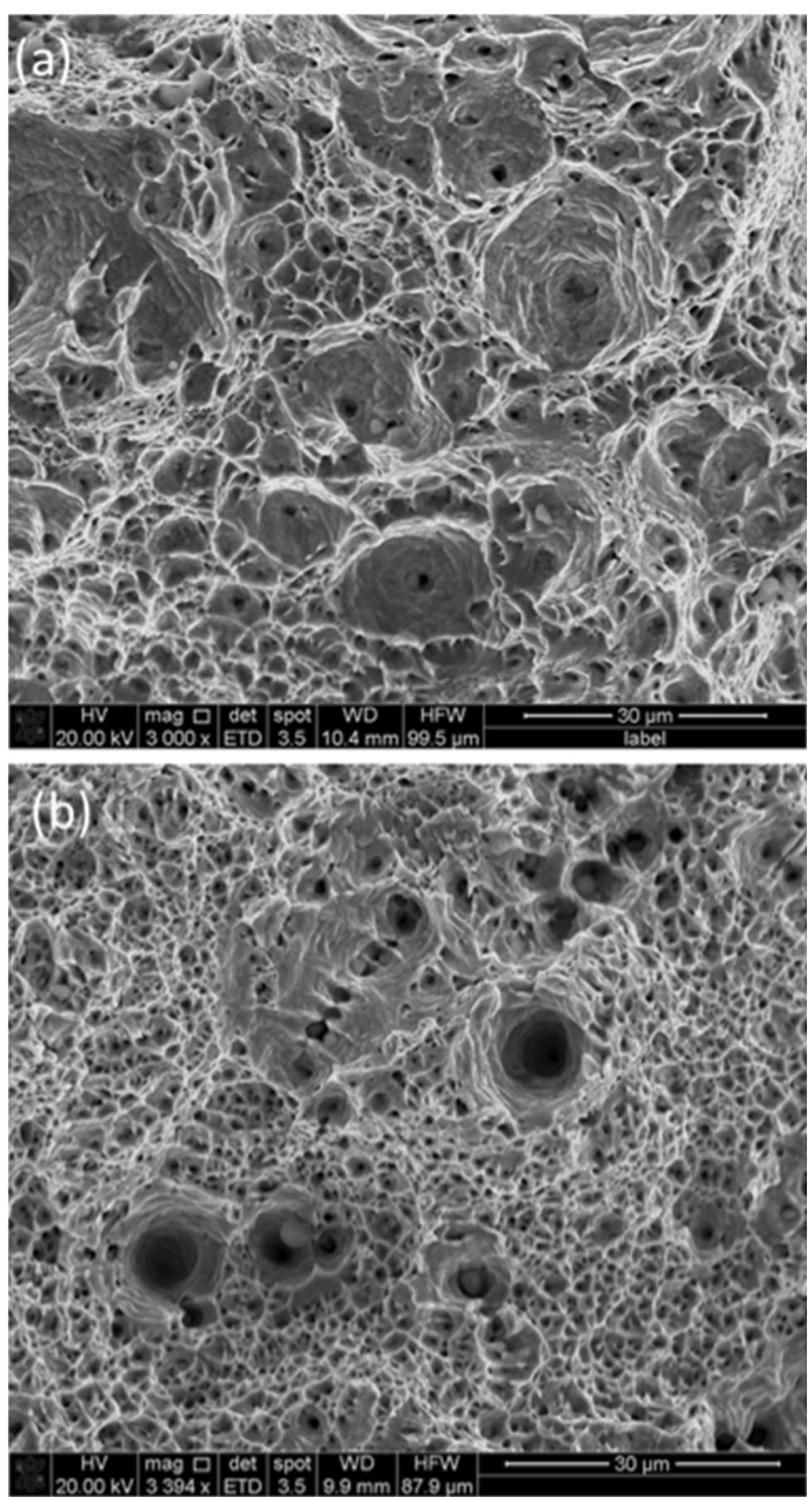

Fig. 10 - Secondary electron images showing typical fracture surfaces for $(a)$ F316L and (b) HIP145.

forged specimens. In addition, the nearest neighbor distance between the larger voids appears to be smaller in the HIP specimen than the forged specimen, which is consistent with the damage below the fracture surface in Figure 8.

The average size of the ductile dimples was measured for each specimen using a linear intercept method as detailed in Section II. Despite the fracture surfaces exhibiting bi-modal distributions of voids, which are thought to originate at different sized particles, the average ductile dimple diameters were measured over the entire fracture surfaces, i.e., averaging all of the ductile dimples irrespective of their size.

Figure 11 shows how the average ductile dimple diameter varies as a function of oxygen content, where the error bars represent the standard deviation of the diameter measurements. A power law regression fit has been applied to the average diameter as well as the upper and lower bound limits of the standard deviation bars. The ductile dimple diameters of the HIP specimens are on average significantly smaller than those of the F316L specimen; however, a trend between the various HIP heats is difficult to determine. The standard deviation of the data is significantly larger for F316L than HIP material, and the standard deviation increases when decreasing oxygen content from 145 to $100 \mathrm{ppm}$ oxygen.

\section{DISCUSSION}

Although the 316L materials contained substantially different concentrations of oxygen, it proved challenging to perform direct comparisons of strength and ductility between the different heats due to large variations in grain size and interstitial alloying elemental composition. It is well known that the addition of nitrogen in austenitic stainless steels acts as a strengthening mechanism, ${ }^{[38]}$ shown through the development of the 'LN' austenitic stainless steel grades, in which carbon is removed to prevent the formation of chromium carbides at grain boundaries, and where carbon is replaced by nitrogen in order to counter the consequent reduction in strength. The reason nitrogen is an excellent substitute for carbon lies in nitrogen's similar atomic radii and ability to manifest itself interstitially within the FCC austenite lattice, thereby providing a strengthening mechanism in the form of energetically unfavorable dislocation interaction.

As reported previously, ${ }^{[13-16]}$ the oxygen remaining in the austenite matrix manifests itself in the form of non-metallic oxide inclusions, such as $\mathrm{Cr}_{2} \mathrm{O}_{3}$ and $\mathrm{MnO}$, and these oxide particles act as stress concentration sites for the initiation of microvoids during plastic deformation. This reduced spatial distribution of microvoids, due to higher volume fractions of particles, facilitates the onset of failure, since the distance over which voids are required to grow before coalescing with neighboring voids is significantly reduced and smaller levels of plastic strain are required. Whereas the influence of oxide particles has been shown to affect the ductile fracture behavior $^{[13-16]}$ in HIP Type 300 stainless steels, the data herein suggest that large variations in oxygen concentrations have little impact on the 0.2 pct yield strength and UTS of various heats of HIP'd 316L. Using Eqs. [1] and [2], as proposed by Irvine and co-workers, yield strength and UTS values have been estimated based on material compositional chemistry and experimentally determined grain size measurements, and show reasonable agreement with the experimentally determined yield strength and UTS values. Figure 2 shows the comparisons between experimental and calculated yield and UTS, showing reasonable agreement with consistent error of $c a$. 15 pct.

Despite the considerable inaccuracy between the experimental and predicted yield strength (mean pct error $=14.9 \mathrm{pct})$ and UTS (mean pct error $=15.9 \mathrm{pct})$ data when using the as-proposed formulae, the percentage error between calculated/experimental yield strength and UTS values does not appear to be related to the oxygen concentration of the specimens; Figure 3 shows 


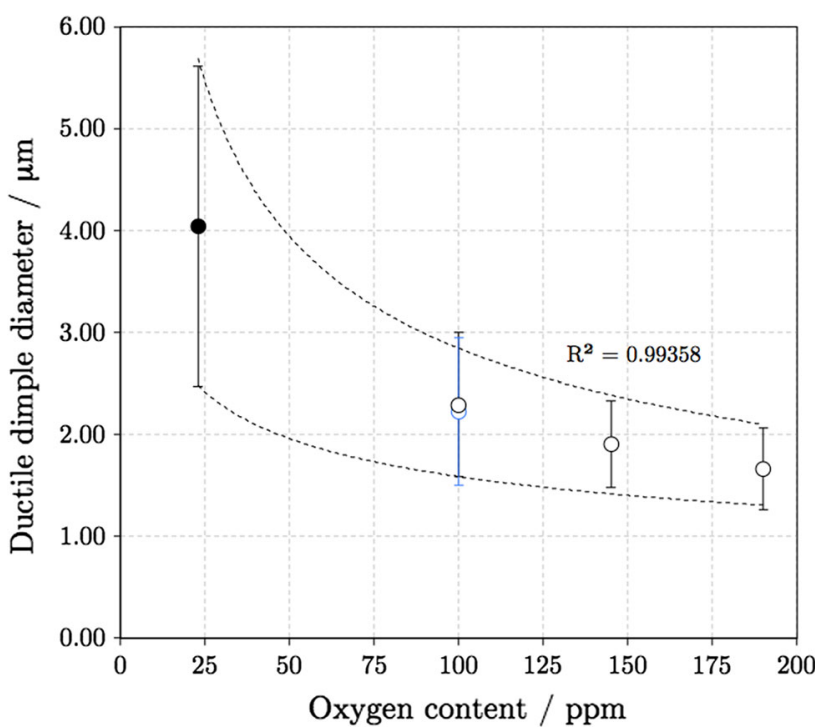

Fig. 11-Average ductile dimple diameter as a function of oxygen content. The error bars express the standard deviation of the data.

the experimental/calculated pct error as a function of oxygen in the specimens, and there is no discernible trend in the data. This is significant, since the concentration of oxygen in the specimens ranges by nearly an order of magnitude, and this appears to not affect the degree to which Eqs. [1] and [2] under- and over-predict yield strength and UTS, respectively. If oxygen were to play a significant and measureable role in affecting yield and UTS, then the magnitude of discrepancy between experimental and calculated yield and UTS would be proportional to the oxygen concentration in the specimens, since Eqs. [1] and [2] only account for material chemistry and grain size; however this is not the case.

There could be several reasons why Eq. [1] underestimates yield strength; the equation has been derived from a range of austenitic stainless steels, and although the authors report excellent agreement with austenitic stainless steels, the numerical factor of 4.4 in the equation is a regression parameter, rather than a microstructurally determined coefficient. $\delta$-ferrite was not observed in the microstructure of the materials herein, and has therefore not been used in this calculation. It is unclear why Eq. [2] overestimates UTS for all the materials, but again could be related to the numerical factor of 29 and, perhaps, the degree of microstructural twinning in the microstructure, since the stacking fault energy affects the work hardening rate and therefore tensile strength. ${ }^{[31]}$

By iteratively adjusting the numerical factors in Eqs. [1] and [2] to 7.2 and 21, respectively, it has been possible to reduce the pct error between experimentally determined and calculated yield strength and UTS values for all the specimens. The improved predictions are presented in Figures 4 and 5, and show that the mean pet error has been reduced to 1.25 and 1.29 pet for the yield strength and UTS, respectively. Using the corrected numerical factors in Eqs. [1] and [2], Figures 6 and 7 highlight the excellent agreement between experimental and calculated yield strength and UTS. Given that the effect of grain size has been removed, and values are therefore a function of nitrogen and carbon concentration alone, this indicates that differences in oxygen concentrations between $23 \mathrm{ppm}$ and 200 ppm have very little, if any, measurable impact on material strength. It should be noted that we have normalized yield and UTS against the average grain size, which will incorporate an error based on the standard deviation of the grain size.

It is possible that any dissolved oxygen remaining in the austenite microstructure might act as a strengthening mechanism, like that of carbon and nitrogen. However, the solubility of oxygen in austenitic stainless steels is relatively small compared to nitrogen and oxygen, thought to be due to (a) the steric effects of the comparatively large $\mathrm{O}^{2-}$ anion radius to the austenite lattice $^{[39]}$ and (b) the presence of alloying elements such as chromium, vanadium, manganese, and silicon and their high affinity for oxygen thus resulting in the formation of secondary phase oxide inclusions. ${ }^{[40]}$ The solubility of oxygen in pure austenite, "solubility" being defined as the maximum limit that can be accommodated by the austenite lattice before resulting in a separate oxide phase, is difficult to measure, partly due to chemical impurities in the austenite lattice and the difficulty associated with establishing equilibrium with the solid phases present. ${ }^{[39]}$ Nevertheless, the solubility of oxygen in pure austenite has been estimated to be on the order of $<30 \mathrm{ppm}^{[39,41]}$ and concentrations in excess of this are assumed to reside in the form of oxide inclusions and secondary phase particles. Regardless of this, the data herein indicate that oxygen concentrations on the order of $200 \mathrm{ppm}$ are not detrimental to a material's yield strength any more than concentrations on the order of $20 \mathrm{ppm}$.

It was initially hypothesized that although oxygen is unable to manifest itself as an interstitial alloying element like carbon and nitrogen, these oxide inclusions might hinder dislocation mobility in a similar fashion to oxide dispersion strengthened (ODS) steels. ODS steels utilize the presence of oxide to improve material strength, ${ }^{[42]}$ and therefore contrast the results presented in this work. This is because the strengthening mechanism in ODS steels is heavily dependent on the size, spacing, and dispersion of the oxide particles. In ODS steels, the oxides are often referred to as nano-oxide dispersions since typical oxide particle diameters on the order of $<100 \mathrm{~nm} .^{[43-47]}$ Mobile dislocations interact with nanometer-sized oxide particles via mechanisms involving direct particle shearing ${ }^{[48,49]}$ and/or circumventing the particle via a bypass manoeuver, such as the looping mechanism as proposed by Orowan, ${ }^{[50]}$ depending on the particle-matrix coherency and degree of bonding between the particle and the matrix, the energy penalty of this bypass mechanism being proportional to the material flow stress. ${ }^{[51,52]}$

However as particle size and spacing increases, their ability to hinder dislocation mobility via individual particle-dislocation interactions diminishes, and their relatively large volumes cause multiple dislocations to agglomerate in the form of dislocation forests on the surface of oxide particles. This has been reported to occur at oxide particle clusters on the order of 


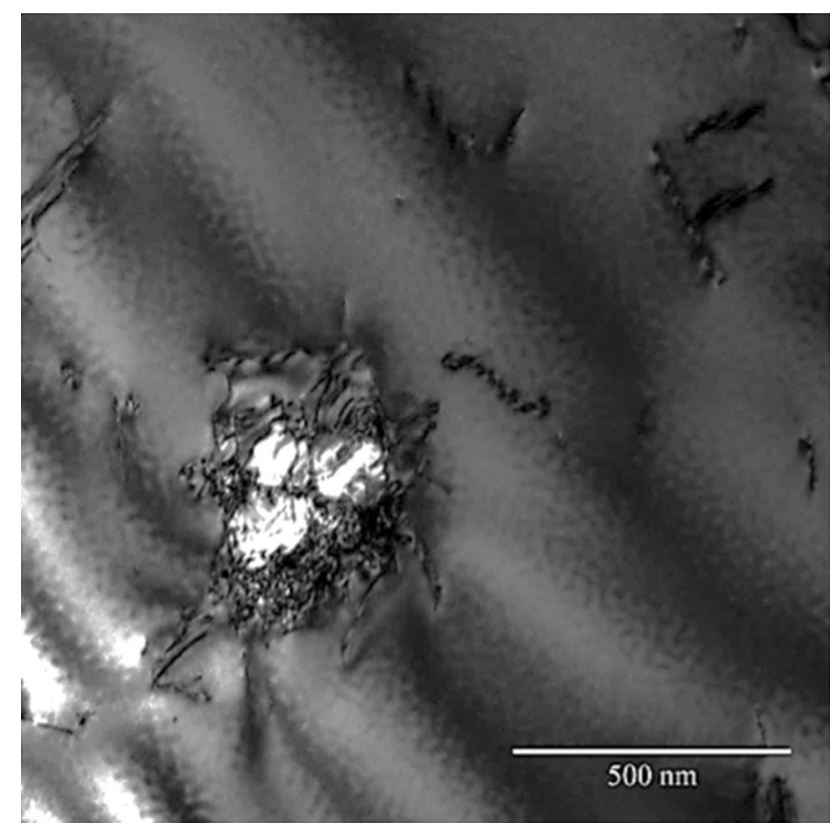

Fig. 12-Transmission electron micrograph showing oxide inclusions in HIP 304L, highlighting the pinning effect which they have on dislocations and thus preventing mobility.

$500 \mathrm{~nm}^{[53]}$ and this is in agreement with observations made by the authors on HIP'd 304L, as shown in Figure 12. This is consistent with the work presented herein, whereby mean particle diameters have previously been shown ${ }^{[14]}$ to be on the order of $c a$. $600 \mathrm{~nm}$. In order for particles to have a strengthening effect, they must exist as a fine dispersion and exhibit good cohesion with the matrix, thus permitting the stress at the dislocation-particle interface to approach the theoretical shear stress of the crystal lattice and initiate yielding on the reverse face of the dislocation barrier. However, if poor cohesion exists between the particle and the matrix, the local stress concentration can initiate the growth of microvoids surrounding the secondary phase particles, which ultimately results in ductile fracture. ${ }^{[51]}$

The various stages in the ductile failure mechanism are effectively recorded in the necked region of the tensile specimen, and can be rationalized in terms of ductile void growth behavior; the distance over which voids grow before resulting in coalescence is related to the spatial distribution of the particles that initiate the voids. The specimens with higher oxygen concentrations undergo microvoid coalescence at reduced levels of plastic strain and will therefore be unable to undergo further reduction in cross-sectional area thus exhibiting less lateral ductility. This phenomenon is also highlighted in Figure 8, which shows sectioned tensile test specimens for (a) F316L, (b) HIP100, and (c) HIP190. There is a clear relationship between the extent of ductile damage (initiated voids which have grown under hydrostatic stress) below the fracture surfaces of the specimens and the oxide concentrations in the microstructure. This is quantified in Figure 9, where the extent of ductile damage, up to $c a$. $400 \mu \mathrm{m}$ below the fracture surface, has been characterized in terms of void area fraction and nearest neighbor distance between voids, and plotted as a function of oxygen concentration for each specimen. It is apparent that $\mathrm{F} 316 \mathrm{~L}$ exhibits a significantly larger average nearest neighbor distance between ductile damage voids than in any of the HIP'd specimens; however, the standard deviation bars associated with the HIP'd specimens make it difficult to judge whether the trend between average nearest neighbor distance and oxygen content is statistically significant. The area fraction data are more convincing and these were collected on several areas below the fracture surfaces. Each area is represented as a square in the data and this statistical sampling highlights the spread of the data. Despite the range of measurements, the data suggest that the area fraction of ductile damage is related to the concentration of oxygen (oxides) and a linear regression fit has been applied to the data. HIP190 exhibits the greatest area fraction of ductile voids: $c a$. $1.2 \mathrm{pct}$, and this is approximately double that of HIP100. This is sensible given that the interface between oxide particles and the austenite matrix act as initiation sites for ductile voids during plastic deformation and necking, and although not every oxide particle will initiate a void, a greater number of nucleation sites will lead to an overall greater volume fraction of ductile voids.

Finally, the fracture surfaces of the failed specimens are shown in Figure 10, and both HIP'd and forged specimens exhibited bi-modal distributions of coalesced voids. However, all materials exhibited coarse and fine void networks, and the coalesced voids were noticeably larger in the forged specimens than in the HIP specimens, with large oxide particle-initiated voids on the order of 20 to $30 \mu \mathrm{m}$ diameter in forged $c f$. $10 \mu \mathrm{m}$ in HIP. With respect to the finer network, F316L exhibited voids on the order of $c a .2$ to $5 \mu \mathrm{m}$, while the HIP specimens exhibited voids on the order of $c a .1 \mu \mathrm{m}$.

Quantifying the differences in ductile dimple diameters is complicated by the fact that voids are not solely initiated at oxide particles, but also at finer secondary phase particles such as carbides. Nonetheless, calculating average ductile dimple diameters across both void networks revealed that the HIP'd specimens exhibited a ductile dimple network that was approximately $50 \mathrm{pct}$ finer than that of the forged specimens ( $c a .2 \mu \mathrm{m}$ for HIP cf. $4 \mu \mathrm{m}$ for forged).

The average ductile dimple diameter was measured and plotted for each specimen, together with the standard deviations plotted as error bars. As shown in Figure 11, the average diameter of the ductile dimples becomes finer with increasing oxygen concentration, which is rationalized in terms of degree of possible void growth, as mentioned earlier. This result is significant, since it confirms the relationship between maximum possible void growth and oxygen content, which forms the basis of the hypothesis regarding how oxygen plays a role in the ductile fracture mechanism. The standard deviation of the data is significantly larger for F316L than any of the HIP'd specimens, and the specimen containing the lowest oxygen concentration exhibits a slightly larger standard deviation than that of the higher oxygen content specimens. 


\section{CONCLUSIONS}

HIP'd stainless steels generally exhibit higher strength and ductility than steels manufactured from more conventional production methodologies, and this is usually attributed to their finer grain size and isotropic microstructure. It has been shown that although a large variation in oxygen concentration in HIP steels has a detrimental and quantifiable effect on the ductile fracture toughness properties, the influence of increasing oxygen is unlikely to significantly affect the strength of these materials. Variations in interstitial chemical composition, such as carbon and nitrogen, alongside the grain size have a marked dominating effect on material strength over oxygen, which manifests itself in the form of non-metallic oxide inclusions rather than remaining dissolved in solid solution.

\section{ACKNOWLEDGMENTS}

The authors would like to thank the UK EPSRC for funding (research grant code: $\mathrm{EP} \backslash \mathrm{J} 021172 \backslash 1$ ) of this research project. The authors are grateful to $\mathrm{Mr}$. David Gandy at EPRI for provision of HIP 316L coupons, as well as Rolls Royce for the provision of forged $316 \mathrm{~L}$ plate. Thanks to Dr. Jovin Lim for help in Transmission Electron Microscopy.

\section{OPEN ACCESS}

This article is distributed under the terms of the Creative Commons Attribution 4.0 International License (http://creativecommons.org/licenses/by/4.0/), which permits unrestricted use, distribution, and reproduction in any medium, provided you give appropriate credit to the original author(s) and the source, provide a link to the Creative Commons license, and indicate if changes were made.

\section{REFERENCES}

1. H.V. Atkinson and S. Davies: Metall. Mater. Trans. A, 2000, vol. 31, pp. 2981-3000.

2. H.T. Larker and R. Lundberg: J. Eur. Ceram. Soc., 1999, vol. 19, pp. 2367-73.

3. C. Barre: Adv. Mater. Processes, 1999, vol. 155, pp. 47-48.

4. Y.C. Jeon and K.T. Kim: Int. J. Mech. Sci., 1999, vol. 41, pp. $815-30$.

5. G.A. Rao and M. Kumar: Mater. Sci. Technol., 1997, vol. 13, pp. 1027-31.

6. V. Viswanathan, T. Laha, K. Balani, A. Agarwal, and S. Seal: Mater. Sci. Eng. R, 2006, vol. 54, pp. 121-285.

7. W.B. Burdett: in American Society of Mechanical Engineers, Pressure Vessels and Piping Division (Publication) PVP, (2006).

8. W.B. Burdett: in American Society of Mechanical Engineers, Pressure Vessels and Piping Division (Publication) PVP, 2010, pp. 815-820.

9. W.B. Burdett, P. Hurrell, and A. Gilleland: in American Society of Mechanical Engineers, Pressure Vessels and Piping Conference Proceedings, 2004, pp 153-160.
10. A.S. Helle, K.E. Easterling, and M.F. Ashby: Acta Metall., 1985, vol. 33, pp. 2163-74.

11. H.R. Dugdale and J.B. Borradaile: Powder Metall, 2013, vol. 56, pp. 374-81.

12. S. Irukuvarghula, H. Hassanin, C. Cayron, M.M. Attallah, D. Stewart, and M. Preuss: Acta Mater., 2017, vol. 133, pp. 269-81.

13. A.J. Cooper, N.I. Cooper, A. Bell, J. Dhers, and A.H. Sherry: Metall. Mater. Trans. A, 2015, vol. 46, pp. 5126-38.

14. A.J. Cooper, N.I. Cooper, J. Dhers, and A.H. Sherry: Metall. Mater. Trans. A, 2016, vol. 47, pp. 4467-75.

15. A.J. Cooper, J. Dhers, and A.H. Sherry: 2016, p. V06AT06A012.

16. A.J. Cooper, R.J. Smith, and A.H. Sherry: Metall. Mater. Trans. $A$, 2017, vol. 48, pp. 2207-21.

17. T. Berglund and M. Östlund, 2016, p. V06AT06A014.

18. T.C. Jelfs and W.B. Burdett: in American Society of Mechanical Engineers, Pressure Vessels and Piping Division (Publication) PVP, 2011, pp. 3-6.

19. G. Appa Rao, D.V.V. Satyanarayana, M. Srinivas, and D.S. Sarma: Powder Metall., 2009, vol. 52, pp. 244-49.

20. A. Lind, J. Sundström, and A. Peacock: Fusion Eng. Des., 2005, vols. 75-79, pp. 979-83.

21. L. Arnberg and A. Karlsson: Int. J. Powder Metall., 1988, vol. 24, pp. $107-112$.

22. ASTM A988 / A988M-16: Standard Specification for Hot Isostatically-Pressed Stainless Steel Flanges, Fittings, Valves, and Parts for High Temperature Service, ASTM International, West Conshohocken, PA, 2016.

23. ASTM E8/E8M: Standard Test Methods for Tension Testing of Metallic Materials, ASTM International, West Conshohocken, PA, 2010.

24. ASTM E3-01: Standard Practice for Preparation of Metallographic Specimens, ASTM International, West Conshohocken, PA, 1996.

25. ASTM E112-96: Standard Test Methods for Determining Average Grain Size, ASTM International, West Conshohocken, PA, 1996.

26. A.L. Thiebes, M.A. Reddemann, J. Palmer, R. Kneer, S. Jockenhoevel, and C.G. Cornelissen: Tissue Eng. Part C, 2016, vol. 22, pp. 322-31.

27. ASTM A240/A240M-17: Standard Specification for Chromium and Chromium-Nickel Stainless Steel Plate, Sheet, and Strip for Pressure Vessels and for General Applications, ASTM International, West Conshohocken, PA, 2017.

28. ASTM A180-15: Standard Practice for Hot Isostatic Pressing of Steel, Stainless Steel, and Related Alloy Castings, ASTM International, West Conshohocken, PA, 2016.

29. E.O. Hall: Proceedings of the Physical Society. Section B 1951, vol. 64, p. 747

30. N.J. Petch: J. Iron Steel Inst., 1953, vol. 174, pp. 25-28.

31. K.J. Irvine, T. Gladman, and F.B. Pickering: J. Iron Steel Inst. 1969, vol. 207

32. N. Ohkubo, K. Miyakusu, Y. Uematsu, and H. Kimura: ISIJ Int., 1994, vol. 34, pp. 764-72.

33. K. Shibata, M. Kogita, C.-S. Chen, and T. Fujita: Trans. Iron Steel Inst. Jpn, 1988, vol. 28, pp. 406-12.

34. K. Kako, E. Kawakami, J. Ohta, and M. Mayuzumi: Materials transactions, 2002, vol. 43, pp. 155-62.

35. G.N. Abrams, D.A. Nail, and H.D. Solomon: in MiCon 78: Optimization of Processing, Properties, and Service Performance Through Microstructural Control: a Symposium, ASTM International, 1979, p. 263.

36. S.K. Maity, A.K. Rajak, M.C. Shekhar, and S.D. Singh: Int. J. Sci. Eng. Technol., 2014, vol. 3, pp. 101-108.

37. F. Pickering: Mater. Sci. Technol. 1992.

38. E. Werner: Mater. Sci. Eng. A, 1988, vol. 101, pp. 93-98.

39. J.A. Kitchener, J.O.M. Bockris, M. Gleiser, and J.W. Evans: Acta Metall., 1953, vol. 1, pp. 93-101.

40. A. Šalak, M. Selecká, and H. Danninger: Machinability of Powder Metallurgy Steels, Cambridge Int Science Publishing, 2005.

41. J.A. Kitchener, J.O.M. Bockris, M. Gleiser, and J.W. Evans: Trans. Faraday Soc., 1952, vol. 48, pp. 995-97.

42. R.W.K. Honeycombe: The Plastic Deformation of Metals, 1975.

43. K. Oka, S. Ohnuki, S. Yamashita, N. Akasaka, S. Ohtsuka, and H. Tanigawa: Mater. Trans., 2007, vol. 48, pp. 2563-66.

44. L.L. Hsiung, M.J. Fluss, and A. Kimura: Mater. Lett., 2010, vol. 64 , pp. $1782-85$. 
45. A. Hirata, T. Fujita, Y.R. Wen, J.H. Schneibel, C.T. Liu, and M.W. Chen: Nat. Mater., 2011, vol. 10, pp. 922-26.

46. M.K. Miller, K.F. Russell, and D.T. Hoelzer: J. Nucl. Mater., 2006, vol. 351, pp. 261-68.

47. K. Dawson and G.J. Tatlock: J. Nucl. Mater., 2014, vol. 444, pp. $252-60$.

48. E. Hornbogen and K.-H. Zum Gahr: Metallography, 1975, vol. 8, pp. 181-202.
49. H Gleiter and E. Hornbogen: Metallography, 1965, vol. 12, pp. $235-50$.

50. E. Orowan: Zeitschrift für Physik, 1934, vol. 89, pp. 634-59.

51. G.E Dieter: Mech. Metall, 1961.

52. I.A. Ibrahim, F.A. Mohamed, and E.J. Lavernia: J. Mater. Sci., 1991, vol. 26, pp. 1137-56.

53. K. Teichmann, C.H. Liebscher, R. Völk1, S. Vorberg, and U. Glatzel: Platin. Met. Rev., 2011, vol. 55, pp. 217-24. 